\title{
A Review of methodologies for Fault Location Techniques in Distribution Power System
}

\author{
Ahmed K. Abbas ${ }^{* 1}$, Mazyed Awan Ahmed Al-Tak ${ }^{2}$ \\ ${ }^{1}$ Department of Construction and Projects, University of Anbar, Ramadi, Iraq \\ ${ }^{2}$ Computer Centre, University of Mosul, Mosul, Iraq
}

\author{
Correspondence \\ * Ahmed K. Abbas \\ Department of Construction and Projects \\ Anbar, Ramadi, Iraq \\ Email: Ahmed89at@uoanbar.edu.iq, \\ mazyed.altak@uomosul.edu.iq
}

\begin{abstract}
Since recent societies become more hooked into electricity, a higher level of power supply continuity is required from power systems. The expansion of those systems makes them liable to electrical faults and several failures are raised due to totally different causes, like the lightning strike, power system element failure caused by mechanical aging as well as human mistakes. These conditions impact the stability of the power as well as lead to costly maintenance and loss of output.

This article examines the latest technologies and strategies to determine the location of faults in medium voltage distribution systems. The aim is to classify and assess different strategies in order to determine the best recommended models in practice or for further improvement. Several ways to locate failures in distribution networks have therefore been established. Because faults are unpredictable, quick fault location as well as isolating are necessary to reduce the impact of faults in distribution networks as well as removing the emergency condition from the entire system. This study also includes a comprehensive evaluation of several defect location methods depending on the algorithm employed, the input, the test system, the characteristics retrieved, and the degree of complexity. In order to gain further insight into the strengths and limitations of each method and also comparative analysis is carried out. Then the main problems of the fault location methods in distribution network are briefly expounded.
\end{abstract}

KEYWORDS: Distribution System, Fault location techniques, Transmission line Fault, Artificial intelligence, PMUs.

\section{INTRODUCTION}

Electrical networks include generating, transmission, and distribution networks. The distribution system is the final step in the transmission of power to individual consumers. Because of the rapid growth in human life demands over the last several decades, both power requirements, as well as the number of electric consumers, have expanded. As a result, distribution networks have had to expand distribution lines as well as feeders to meet consumer demand. As society is becoming more dependent on energy, more electric power reliability is needed, as is the development of innovative methods and techniques for detecting and locating problems and restoring power as quickly as feasible.

For several decades, companies and electricity generation specialists have studied the causes of power failures on power distribution systems. The principal cause for energy failures in electricity systems is electric failures, especially those in distribution systems (line-to-ground fault around $70 \%$ ). These defects are caused by a variety of factors, such as failure of facilities, lighting, storms, harmful weather, rain, breakdown of isolations, trees, birds and so on [1][2]. The fast and precise location of faults on the distribution system improves the reliability of the system and supply continuity, faster power supply recovery and therefore lower service shutdown times. Different strategies are being suggested to allow operational engineers to find the fault as quickly as feasible, based on the essential problems of failure location.

In contrast to distribution systems, much of the techniques for locating faults apply to transmission lines. Because of several parallel branches, several taps along with feeders, several conductors, and a complicated structure, besides from a lack of monitoring equipment, there is a lack of communication and information transportation systems so the locating faults in distribution systems is a difficult process [3]. In this study the most up-to-date technologies and categorize and analyze various techniques identifying location of the fault on distribution systems depending on the algorithm employed, the input, the test system, the characteristics retrieved, and the degree of complexity are 
reviewed [4]. With the goal of identifying the most recommendation models for practical application or further enhancement. A thorough analysis of the various strategies for fault site estimates and categorization has been offered. The rest of the research review paper is prepared as follows: Section II illustrates Kinds of Fault methods. Section III discusses the Fault Location Methodologies. Eventually, the conclusion of this paper is introduced in section IV.

\section{KINDS OF FAULT}

The two kinds of fault that are commonly found in distribution networks are series and shunt fault [5]. There are many different sorts of faults that can arise in a power system. Figure 1 presents the categorization of each set of faults.

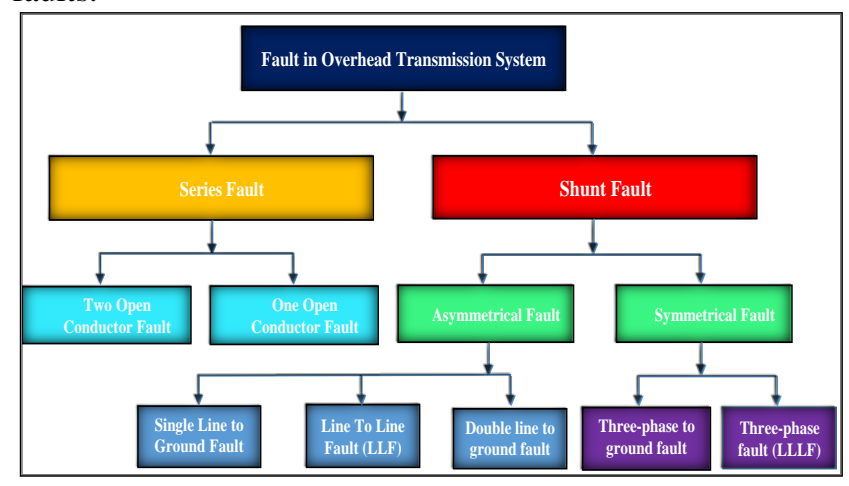

Fig. 1: presents the categorization of each set of faults.

\section{A. Series Fault}

When there is an unbalanced series impedance on even a line, a series failure happens. It symbolizes a conductor that is open. When one or even more lines in a power distribution system have a broken line or impedance, a series failure happens. Frequency, voltage increase, as well as current drop at the problematic phases are used to classify series failures.

\section{B. Shunt Fault}

Shunt faults are common in distribution networks. For identifying as well as isolating the failed circuit in a distribution network, phase overcurrent relays, as well as ground-overcurrent relays, are widely utilized. Shunt faults are distinguished by an increase in current as well as a decrease in voltage and frequency. Shunt faults are divided into symmetrical and asymmetrical faults by the Shunt Fault divider [6]. Asymmetrical faults have been categorized as (SLGF), (DLGF), and (LLF). Three-phase to ground faults (LLLGF) and three-phase faults (LLLF) are the two categorized for symmetrical faults.

\section{1) Single Line To Ground Fault (SLGF)}

A single ground fault line (SLGF) is also called a short circuit fault. It happens when the ground or neutral wire touch one phase of the transmission line. Winds, falling trees, or any other catastrophe are some of the causes of SLGF[7]. Approximately $70 \%$ of network issues fall into this category.

\section{2) Line To Line Fault (LLF)}

Because of heavy winds or two conductors make short circuits there is a line-to-line fault. It can happen on either overhead or underground electrical lines. One of the peculiarities of LLF is that the amplitude of fault impedance can fluctuate widely, making it impossible to estimate its bottom and upper limits. Line to line errors account for $15 \%$ of all system failure.

\section{3) Double line to ground fault (DLGF)}

Double line to ground fault will occur when a falling tree connects two phases with the ground. A DLGF is a severe occurrence that causes severe asymmetry and can turn into a three-phase fault if not resolved within a particular amount of time. DLGF failures account for $10 \%$ of all defects.

\section{4) Three-phase fault ( $L L L F)$}

A three-phase failure in electrical network has been the most severe as well as produced by a concomitant short circuit among all three lines while the least serious failure is a single line to the ground. There are no LLLFs commonly and less than $5 \%$ of the line failures exist

\section{5) Three-phase to ground fault (LLLGF)}

The symmetrical defect is also referred to as the three phase to ground fault (LLLGF). It can happen by a breakdown of the equipment, collapsing tower or a line which connects the rest of the phases. In the actual world, LLLGF is uncommon, accounting for just $5 \%$ of line faults. Even though it is the least common fault, it would be the most harmful. The threephase-to-ground fault properties are voltage levels that are equivalent to zero, and the fault current is high.

The seriousness of the fault can be characterized according to the size of the fault current and its destructive potential. Table I below shows the proportion for every type of defect and its severity.

TABLE I

SHOWS THE PROPORTION FOR EVERY TYPE OF DEFECT AND ITS SEVERITY [5].

\begin{tabular}{|c|c|c|c|}
\hline Fault & $\begin{array}{c}\text { Percentage of } \\
\text { Occurrence }\end{array}$ & Severity & Simplicity \\
\hline SLGF & $70 \%$ & $\begin{array}{c}\text { Less } \\
\text { severe }\end{array}$ & Very low \\
\hline LLF & $15 \%$ & $\begin{array}{c}\text { Less } \\
\text { severe }\end{array}$ & Low \\
\hline DLGF & $10 \%$ & $\begin{array}{c}\text { Less } \\
\text { severe }\end{array}$ & Moderate \\
\hline $\begin{array}{c}\text { LLLGF, } \\
\text { LLLF }\end{array}$ & $5 \%$ & $\begin{array}{c}\text { More } \\
\text { severe }\end{array}$ & Very high \\
\hline
\end{tabular}

\section{FAult Location Methodologies}

The works on fault location detection in distribution systems may be surveyed and divided into two major teams:

i) Non-electrical data based methodologies, and ii) electrical data-based methodologies. The classifications of each group are illustrated in Fig. 2. 


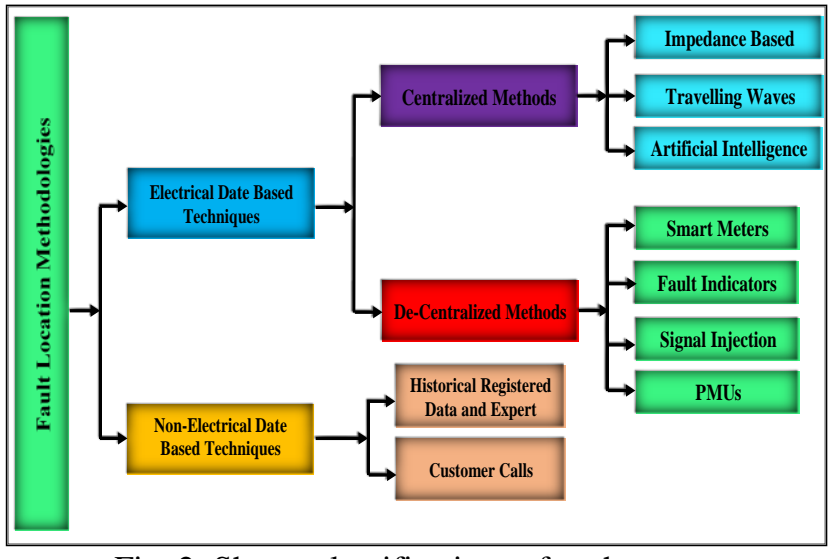

Fig. 2: Shows classifications of each group.

\section{A. Non-Electrical Date Based Techniques}

None-electrical technologies were the earliest crude approaches for the detection of failure points due to a lack of technological advancements. These strategies are based on private information, technical expertise, history preserved, weather data, etc. Non-electrical techniques are simple as a less precise and time demanding approaches, which are the primary defects[9].

- The most conventional way for identifying faulty regions is customer calls. If problems (such as errors) are present in a system, a particular part of the network may be deactivated. Customers in locations where there is a power outage are more likely to phone the utility provider to report the outage. The utility provider can limit down the faulty area by having the consumer's location[9][10][11][12]. There are several drawbacks to user call methods: for nighttime defects, there might be a small number of customer calls, which prevent the reporting of an interrupted area which is otherwise difficult. Fake calls involve aid to be performed as true, else it will cause a false assessment and time consumption[13][14].

- The researchers have used rough set Theories as a tool to create appropriate patterns and rules for defective machine diagnostics and localization of failure in the distribution network, historically registered data and expert knowledge techniques for fault[15][16]. Data mining is a computer intelligence area introducing novel strategies and processes for substantial data processing. One of data mining theories that may be used to explain the infrequent correlations between equipment failure as well as evidence regarding perceptions during feeder outages and the surrounding settings is rough set theory[17].

\section{B. Electrical Date Based Techniques}

Recent technologies and the new era of communication channels have encouraged the transmission of data gathered into control centers, which have resulted in the development of electrical approaches. Compared with non-electrical approaches, the key benefits of such approaches are their enhancing time and reliability to detect failures[9][18]. In general, electrical data based fault location techniques include two main groups will be discussed below, which are differing in the positioning of the measuring point in the network and transferring the data obtained to control centers, are categorized into

(i) Centralized methods

(ii) Decentralized methods.

A detailed description in the following paragraphs of electrical date-based approaches.

\section{1) Centralized methods for fault location methods}

With regard to centered techniques the metering equipment at the main station are executed and the measured values are utilized to indicate the position of the defect. While the measurements of various feeders as well as buses are transferred using the decentralized techniques to the control center with proper communication links to discover the defective locations. Impedance-based-techniques, travellingwave-techniques, and artificial-intelligence techniques are the main centralized techniques.

\section{a) Impedance based methods}

Impedance-based-techniques in electricity utilities are popular because they are simple and cost effective in comparison with the travelling wave technique. In the impedance-based technique, the impedance value is used as observed from the error location measuring node [6]. For impedance computation, the voltage and current measurements are used. From the computed apparent impedance, the fault distance from the measured point to the fault position may be inferred. Since this impedance corresponds to its overall length, the distance to the fault location is calculated by the unit length from the recorded impedance.

Overall, the fault impedance, as unknown which is the one of the key obstacles in finding faults locating. For both radial and looping systems in the presence of distributed units, impedance based philosophy is employed in [19][20].

\section{b) Travelling wave techniques}

If a fault occurs in a power system, transient voltages and currents known as traveling waves (impulse) are formed at their fault location and propagated to both ends from that point away [21]. This approach is traditionally based on monitoring the time of arrival of the fault-initiated travel wave at one or more terminals. That the traveling waves between the terminal line and the Fault position are transported and reflected [22]. The fault distance may be easily computed if the arrival time and the rate of wave propagation are specified. Applying this technique to distribution networks gives a better answer for a fault location if distribution network discontinuities are not considered [23][24].

Figure 3 shows the waves caused by refraction and a power line failure, where $\mathrm{v}$ is the traveling wave's propagation velocity in the line and $\mathrm{t} 1$ is the time it takes the traveling wave to go from the measurement node to the fault point. T2 is the time from of the fault point to the node [25][26][27] for the reflected wave. The distance is determined by equation (1) [16] below. 


$$
d=v \times \frac{\Delta \mathrm{t}}{2}
$$

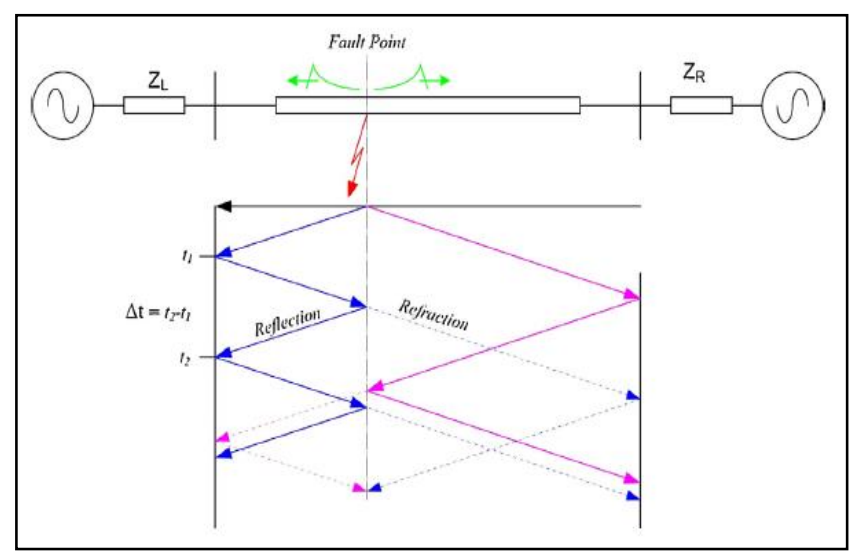

Fig. 3: Waves caused by refraction and a power line failure.

Nevertheless, it is a huge issue in distribution networks to identify the proper reflection produced by the failure due to the various reflections of injected impulses from side lines and branches lines. That makes it difficult to employ these technologies in distribution systems. Investigation aims on how to apply the fault location approaches based on traveling waves at MV levels[28].

\section{c) Artificial intelligence based methods}

In order to detect defects[6], a knowledge-based technical approach has been used because of the complexity of distributing systems and different uncertainties which are difficult to solve using traditional approaches. The approach in general needs data including such feeder measurements, sub-station as well as feeder switch state, fault detection data management placed across feeders and environmental conditions. It is possible to analyze this data using artificial intelligence algorithms.

Artificial intelligence (AI) is classified as a sub-field of computer engineering which investigates how machines might imitate the thinking and activities of human beings. AI approaches, for example, are implemented Artificial Neural Network (ANN), Fuzzy Logic (FL), Experts' System (ES), Support Vector Machine (SVM), Deep Learning as well as genetic Algorithm (GA) In addition to preventing human errors, the time-factor for discovering incorrect spots is greatly reduced [29]. For each type of problem, AI approaches require a data set, with roughly $20 \%$ of the information needed to educate the algorithm and the rest needed to identify the faults[3][30].In Refs. [31][32]surveyed different algorithms to locate fault based on ANN and FL respectively. Despite the precision and short execution time of AI-based methods, the most significant disadvantage of these techniques is the requirement for various real or simulated fault cases for modeled Artificial intelligence training. In addition, like other fault location strategies, these methods are based on substation measures, fault distance assessments instead of the fault location or associated bus, and thus they may detect different locations for the same fault distance [7]. Table II, gives an outline of the advantages and drawbacks of the centralized methods.

TABLE II

AN OUTLINE OF THE ADVANTAGES AND DRAWBACKS OF THE CENTRALIZED BASED METHODS.

\begin{tabular}{|c|c|c|}
\hline Method & Advantages & drawbacks \\
\hline $\begin{array}{l}\text { Impedance } \\
\text { based }\end{array}$ & $\begin{array}{l}\text { - Simple } \\
\text { implementation } \\
\text { - Cost-effective }\end{array}$ & $\begin{array}{l}\text { - Time consuming due to } \\
\text { laterals } \\
\text { - Fault type identification } \\
\text { - Multiple location } \\
\text { estimation } \\
\text { - Dependent on line } \\
\text { parameters }\end{array}$ \\
\hline $\begin{array}{l}\text { Travelling } \\
\text { wave }\end{array}$ & $\begin{array}{l}\text { - High accurate } \\
\text { - Independent of } \\
\text { network data }\end{array}$ & $\begin{array}{l}\text { - Un required reflections } \\
\text { due to laterals } \\
\text { - Complex } \\
\text { implementation } \\
\text { - More expensive } \\
\text { - Required High } \\
\text { sampling rate of fault } \\
\text { recorders. }\end{array}$ \\
\hline $\begin{array}{l}\text { Artificial } \\
\text { intelligence }\end{array}$ & $\begin{array}{l}\text { - Short } \\
\text { execution time }\end{array}$ & $\begin{array}{l}\text { - May report multiple } \\
\text { locations } \\
\text { - A significant amount of } \\
\text { training data } \\
\text { - Continuous training to } \\
\text { include network changes }\end{array}$ \\
\hline
\end{tabular}

\section{2) Decentralized methods}

The most popular technologies of default location, especially with advances in smart grid technology, will probably be the decentralized ways [33]. The decentralized fault location process is become easy. With increasing intelligent electronic device (IED) as well as other installations in distribution systems and communications advancements, are able to identify a defect and transmit a signal to the control room, indicating the fault situation. The dispersed IEDs can determine the fault location on a local level, alternatively, upper-level systems can use measurements from sensors along the feeder to deduce the damaged line section. Since the contemporary smart grid is equipped with monitoring and communication, ready auxiliary substations, the secondary substations as well as switch units are natural places for equipment that enable decentralized fault localization.

These measurements are then utilized to execute the fault location algorithms. The decentralized methods include; smart meters, fault passage indicators, signal injection and Phasor Measurement Units (PMUs) based methods. Figure 4: shows the Decentralized failure location in secondary substations depending on fault indicators[34].

\section{a) Utilization of smart meters}

Motivated by current developments in monitoring and communication systems for distribution networks, In various research studies, the uses of developing metering as well as communications technology for electric power distribution systems are now investigated[35][36]. Smart meters are 
electronic estimation devices that utilize the utilities to get data for charging purposes, observing, controlling and operating electric systems remotely[37]. Ref [38] provided an approach which was based on the fact that "when a failure occurs on a feeder, the voltage dropping increases, and each feeder node has different characteristics." The problematic node or a problematic feeder area can be detected with the help of intelligent meter measurements and knowledge of its properties of the voltage sag.

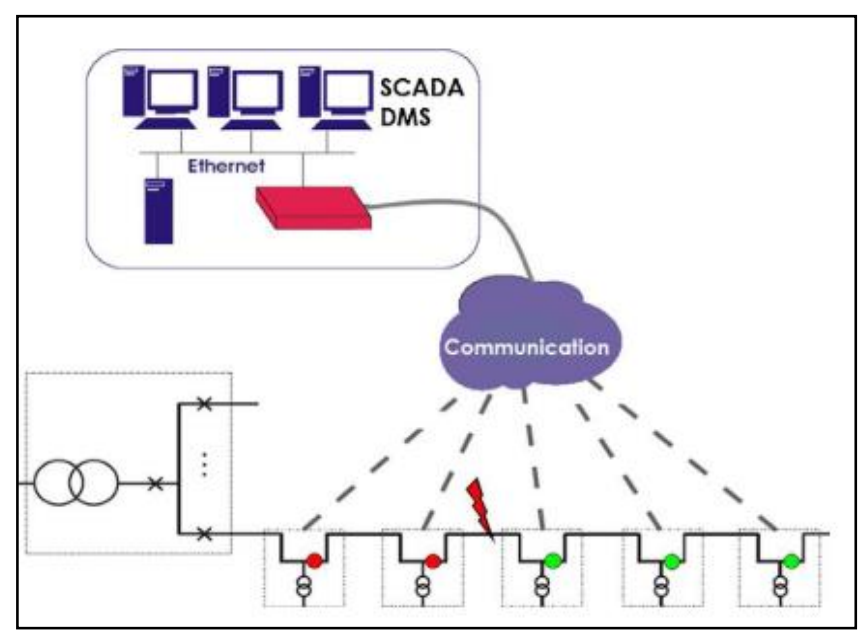

Fig. 4: Decentralized failure location in secondary substations depending on fault indicators.

Smart meters are used by authors in[39] to restrict the search region to discover issues. The upstream protection device opens the circuit whenever a fault occurs on the system in this situation. A fuse, recloser, or substation relay could be used as such protection device. All consumers downstream are deenergised, the communication between Feeder, consumer meters as well as control center will therefore allow for monitoring the deenergized meter and hence the detection of the deenergised part of the network. Applications in the failure location are among the most exciting. An impedance-based fault localization algorithm is used to assess the failure distance and identify all feasible fault locations for the integrated approaches suggested in[40][41]. The smart meters are then used to identify the right solution by using the voltage monitoring abilities. Although these integrated approaches can tackle the many issues of estimating impedance based techniques, there is still no solution for the problem of sensitivity to load inaccurate data. The most significant flaw with smart meterbased approaches is that they assume that systems are normally balanced (the phase difference between the three phases equals 120 degree), which is untrue. Furthermore, many smart meters are necessary to detect the impacted area properly. Note that any meters failure will lead to an incorrect detection of the defective portion[42].

\section{b) Fault Passage Indicators}

Innovations recognized in particular to identify short faults are Fault Passage Indicators (FPIs).Reliable FPIs with connection to higher-level data systems enable SCADA, for example, to visualize the fault current's path to the operators inside the control center][18][43]. These error indications allow distribution network operators to rapidly detect the problematic network area and restore customers' power supply to healthy portions[18] . Ref. [9] Provides a discussion of several FPI generations detailing their development, effectiveness and limitations, and the causes for this development. The FPI module consists mainly of reed switches and alert LEDs. The attractive force actuated by the fault current flows through the line segment magnetizing the reed switch closing a few contacts and flashing power Led for a fault sign. The problem exists between the last fault indication that has been enabled and the first indication that is still inactive. The route of the defective current is indicated by the triggered indicators from of the feeding point to the defective region. The control center can collect fault data by the communication network and display the data in a graphical user interface [44].

Another FPI based method was explained in ref.[4] Which utilized the changes in symmetrical component currents after fault occurrence. It depended on measuring the change in negative sequence and zero-sequence currents at the same point. According to the method, the negative sequence current is or could be notable under the fault site with small changes from the feeding substation up to the fault site, but it is meaningless after the fault site. Based on this strategy, the measuring point was within the fault path in case that the change in zero sequence and negative sequence currents exceeded their limits at the same time the development of these approaches is supported by enhancements in sensor communication and information technology in secondary substations. One of the disadvantages of the FPI based approaches is that just the faulty portion and not the exact location of the problem are identified [45]. Nevertheless, this isn't a big issue because in many situations, simply identifying the faulty portion is enough.

\section{c) Signal Injection-Based Methods}

Approaches based on pulse injection and on injection of nongrid-frequency current have been proposed. There have been suggestions for methods that are based on pulse injection and non-grid-frequency current injection [5]. Signal detection as well as communications are necessary in additional to injection. The aim is to inject a pulsing current into the system neutral after the problem happens. The diagnosis current is determined by sensors in the comparison line. By measuring the zero sequence current utilizing relays scattered throughout the feeder the determination of the faulty segment is performed. Then the measurement collected from all detectors are sent to the control centers by means of the communication systems and consequently, the fault line can be detected by comparing the results [46]. Nevertheless, there are some extra requirements in this conventional pulse technique. Concisely, injection-based strategies need injection devices at the main substations which will cause more complications and confrontations. One of the biggest limitations is that the failure has to be around $25 \mathrm{~s}$ apart from its capability to identify defects other than mild ohmic faults. In addition to injection devices, signal detectors are required to identify the injected signals. 
Additionally, for unearthed neutral systems, these techniques are not suitable. In general evaluations and overviews, these techniques have gotten little attention. Although the pulse detection procedure idea is extremely ancient, and in compensation systems, the approach is widespread [47].

\section{d) Phasor Measurement Units based techniques}

PMUs is among the successful findings of the study that started in Virginia Tech in the early 1980s utilizing a global positioning system (GPS), It is capable of providing synchronized measurements of real-time voltage as well as current phasors. The same time signals are used to synchronize with the GPS. The presentation of PMUs in power systems essentially moves forward the conceivable outcomes for observing as well as studying the dynamics of power systems. Synchronized measurements allow for direct determination of phase angles among matching phasors in a variety of locations within the power system [48]. The benefit of referencing phase angle to a global reference is that it allows for a broad snapshot of the power system to be captured [49]. PMUs' contributions to wide-area monitoring provided the impetus for this study, which is able to provide the following measurements (synchronously): Phase angle of voltages and currents. Protection, and control systems, Local frequency, Power factor, this section looks at several fault localization techniques, which are one of the protective applications made possible by the presence of PMUs. Figure 5: Basic block diagram of Phasor Measurement Units operation.

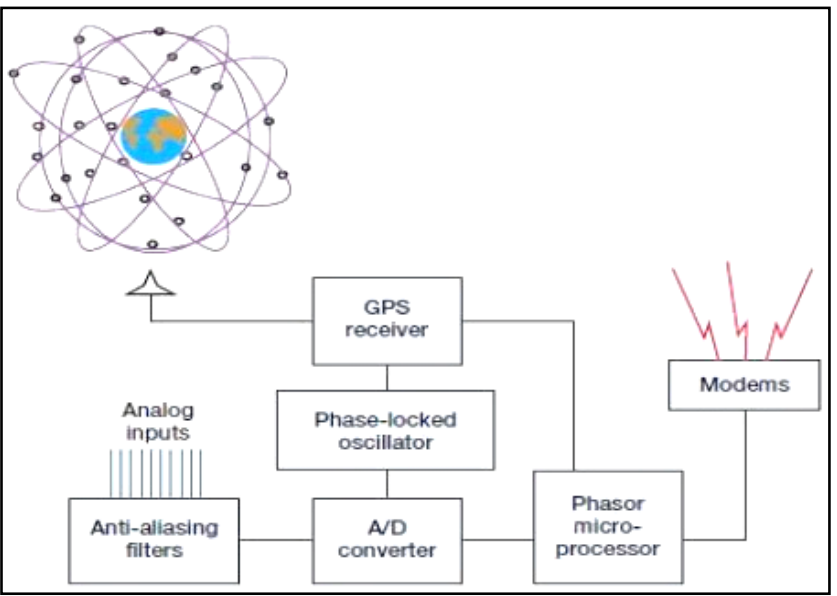

Fig. 5: Basic block diagram of Phasor Measurement Units operation.

In this section, some of the techniques that use PMUs to identify the fault location are described. In [50], the researcher proposed a strategy for fault location in distribution systems utilizing compressive sensing. Voltages were measured by PMUs along the feeders during fault and prefault. The voltage droop vector and impedance matrix were combined to get a current vector with a nonzero component corresponding to the faulted bus. The proposed method had the ability to recover signals from few measurements, as the current vector was obtained, then faulted point could be identified. In[51], the researchers suggested a technique that employs the observed voltage as well as current from the PMU at a single terminal. The method is based on dividing distribution system into line segments, by repeating each line segment (section), a fault distance is obtained. This distance represents the proportional distance between the endpoints of the line segment. If the determined distance is less than 1.0, a fault can be indicated for the corresponding line segment such, else the next line segment of the model can be analyzed. Recently, PMUs for diverse uses, have already been placed in multiple utilities worldwide [52], including such postmortem analysis, adaptive protection, system protection systems and state estimates, The use of phasor measuring units to build fault location algorithms as a protective application was studied in latest literature.

Based on the researches in Ref.[53][54][55][56][57], approaches dependent on the real time data supplied by PMUs exhibited a high degree of accuracy, precision and less impact from the factors surrounding them, including such fault resistances, in finding the fault site in less time. Although these units make improvements to the techniques used to locate a fault, a key difficulty is the high cost of the devices for most of these techniques, this can be prevented by using an appropriate method of optimization for allocating these devices to power networks while attaining least cost. The objective is therefore the identification of the optimum number of these devices as well as their greatest positions whilst keeping the grid fully observable[58][59][60][61][62]. Table III: illustrates the advantages and drawbacks of surveyed decentralized methods (smart meters based, FPIs based and Signal injection-based and PMU based).

TABLE III

ILLUSTRATES THE CHARACTERISTICS OF SURVEYED DECENTRALIZED BASED METHODS

\begin{tabular}{|c|c|c|}
\hline Method & Advantages & Disadvantages \\
\hline $\begin{array}{l}\text { Smart } \\
\text { meters- } \\
\text { based }\end{array}$ & $\begin{array}{l}\text { - Simple } \\
\text { implementation } \\
\text { - Accurate }\end{array}$ & $\begin{array}{l}\text { - Require a lot of smart } \\
\text { meters } \\
\text { - Requirement of an effective } \\
\text { communication network } \\
\text { - Failure of any meter cause } \\
\text { location error } \\
\text { - High cost }\end{array}$ \\
\hline $\begin{array}{l}\text { FPIs } \\
\text { based }\end{array}$ & $\begin{array}{l}\text { - Simple } \\
\text { implementation } \\
\text { - High sensitivity }\end{array}$ & $\begin{array}{l}\text { - High cost } \\
\text { - Requirement of an effective } \\
\text { communication network } \\
\text { - Failure of any FPI threats } \\
\text { location identification } \\
\text { - Fault path is followed hardly } \\
\text { in large power systems }\end{array}$ \\
\hline $\begin{array}{l}\text { Signal } \\
\text { injection }\end{array}$ & $\begin{array}{l}\text { - Simple } \\
\text { implementation } \\
\text { - System data } \\
\text { depend less } \\
\text { - Accurate }\end{array}$ & $\begin{array}{l}\text { - High implementation cost } \\
\text { - Require signal injection and } \\
\text { receiver devices which are } \\
\text { costly } \\
\text { - Defect of any signal detector } \\
\text { or communication links } \\
\text { cause misidentification of } \\
\text { faulty point }\end{array}$ \\
\hline
\end{tabular}




\begin{tabular}{|c|l|l|}
\hline & - Simple & - High implementation cost \\
& implementation & - Require a large number of \\
PMU & - Accurately & meters and measuring \\
based & identifying & devices \\
methods & faulty points & - Need a powerful \\
& - Not affected by & communication \\
& laterals and & infrastructure \\
& branches & \\
\hline
\end{tabular}

To make it easier to compare the approaches mentioned in this study, the most crucial primary characteristics, advantages, disadvantages, Requirements, accuracy and execution time in Table IV and V Below summarizes the information for electrical and non-electrical date-based methods.

TABLE IV

THE MAIN ADVANTAGES, DISADVANTAGES, AND REQUIREMENTS OF ELECTRICAL AND NON-ELECTRICAL DATE-BASED METHODS

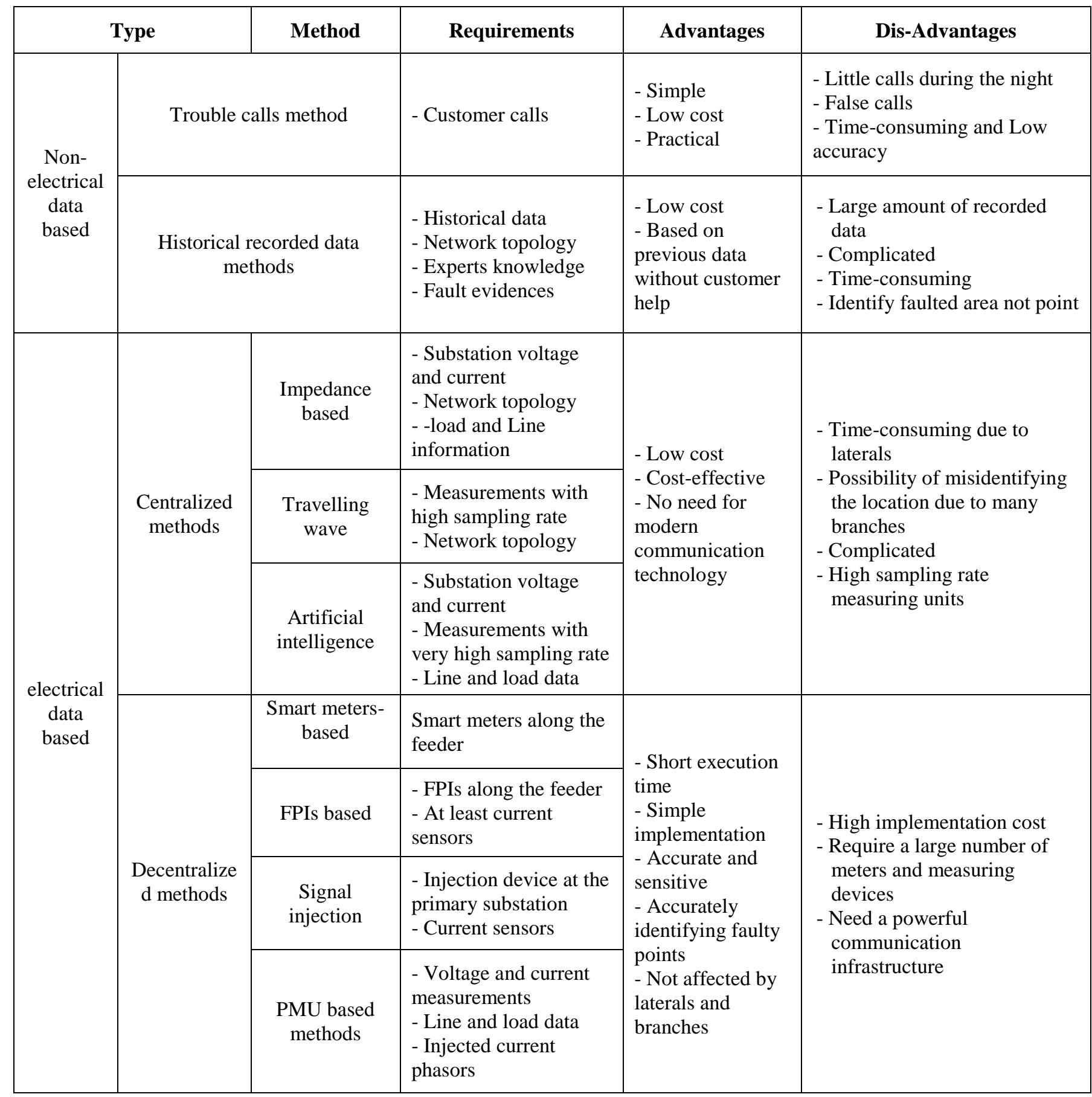


TABLE V

THE ACCURACY AND EXECUTION TIME OF ELECTRICAL AND NON-ELECTRICAL DATE-BASED METHODS

\begin{tabular}{|c|c|c|c|c|}
\hline \multicolumn{2}{|c|}{ Type } & Method & Accuracy & Execution time \\
\hline \multirow{2}{*}{\multicolumn{2}{|c|}{ Non-electrical data based }} & $\begin{array}{c}\text { Trouble calls } \\
\text { method }\end{array}$ & \multirow{2}{*}{$\begin{array}{l}\text { - Low accuracy } \\
\text { - Low sensitivity }\end{array}$} & \multirow{2}{*}{ Time-consuming } \\
\hline & & $\begin{array}{l}\text { Historical } \\
\text { recorded data } \\
\text { methods }\end{array}$ & & \\
\hline \multirow{7}{*}{$\begin{array}{c}\text { electrical } \\
\text { data } \\
\text { based }\end{array}$} & \multirow{3}{*}{$\begin{array}{l}\text { Centralized } \\
\text { methods }\end{array}$} & Impedance based & $\begin{array}{l}\text { Identification of the fault type and } \\
\text { network topology }\end{array}$ & $\begin{array}{l}\text { Lateral time consuming as well } \\
\text { as categorization of faults }\end{array}$ \\
\hline & & Travelling wave & $\begin{array}{l}\text { Precise results for single lines of } \\
\text { distribution and transmission }\end{array}$ & Time consuming due to laterals \\
\hline & & $\begin{array}{c}\text { Artificial } \\
\text { intelligence }\end{array}$ & Accurate based on performed training & Short execution time \\
\hline & \multirow{4}{*}{$\begin{array}{l}\text { Decentralized } \\
\text { methods }\end{array}$} & $\begin{array}{l}\text { Smart meters- } \\
\text { based }\end{array}$ & High accuracy & \multirow{3}{*}{ Time- consuming } \\
\hline & & FPIs based & Accurate and High sensitivity & \\
\hline & & Signal injection & Accurate & \\
\hline & & $\begin{array}{l}\text { PMU based } \\
\text { methods }\end{array}$ & Accurately identifying faulty points & $\begin{array}{l}\text { Time consuming because of } \\
\text { iterating each line segment }\end{array}$ \\
\hline
\end{tabular}

\section{CONCLUSION}

A considerable of effort has been made into the advancement of MV system fault location during the last few years. Given the complexity of the network, it is difficult to detect problem location in the distribution system. However, with recent technological advancements and the mathematical processes, research teams and utility have developed the best approach for determining the fault site in the distribution system. In summary, new and superior techniques of fault location will be developed as long as the distribution system continues to expand in tandem with technological advancements. In distribution systems, the fast find location of the faulted area leads to minimizing of disturbance caused to the influenced clients. The most up-to-date approaches for locating faults in distribution systems were reviewed. Fault location techniques may often be classified into two types, Techniques based on non-electrical data as well as techniques based on electrical data (both centralized and decentralized). This study also includes a comprehensive evaluation of several defect location methods depending on the algorithm employed, the input, the test system, the characteristics retrieved, and the degree of complexity. Consequently, no individual strategy has been shown to be capable of solving all problems because each was established in response to distinct circumstances. Depending on the network complexities and the accessibility of monitoring systems, each technique can address an issue. It is therefore determined that its basic operating principles must be well grasped in order to be effective in a specific technique of localization of problem. In addition, customers can choose techniques that better suit their demands and equipment. Research on the location of faults in distribution systems is therefore active across the world. Due to its wide range of approaches, the right choosing of a technique can be difficult and a time-consuming operation.

\section{ACKNOWLEDGMENT}

The authors would like to thank the Ministry of Higher Education and Scientific Research of Iraq, University of Anbar, University Headquarter, Department of Construction and Projects \& University of Mosul, Iraq, for supporting as for applied this work.

\section{CONFLICT OF INTEREST}

The authors have no conflict of relevant interest to this article.

\section{REFERENCES}

[1] L. Wang, 'The fault causes of overhead lines in distribution network', in MATEC Web of Conferences, 2016, vol. 61, p. 2017. 
[2] S. Authafa, 'Short Circuit Faults Identification and Localization in IEEE 34 Nodes Distribution Feeder Based on the Theory of Wavelets', Iraqi J. Electr. Electron. Eng., vol. 14, no. 1, pp. 65-79, 2018, doi: 10.37917/ijeee.14.1.7.

[3] H. Livani, C. Y. Evrenosoglu, and V. A. Centeno, 'A machine learning-based faulty line identification for smart distribution network', in 2013 North American Power Symposium (NAPS), 2013, pp. 1-5.

[4] S. Hänninen, 'Single phase earth faults in high impedance grounded networks Characteristics, indication and location', VTT Publ., no. 453, pp. 2-78, 2001.

[5] T. Gonen, Electrical power transmission system engineering: analysis and design. CRC press, 2019.

[6] S. S. Gururajapathy, H. Mokhlis, and H. A. Illias, 'Fault location and detection techniques in power distribution systems with distributed generation: A review', Renew. Sustain. Energy Rev., vol. 74, no. March, pp. 949-958, 2017, doi: 10.1016/j.rser.2017.03.021.

[7] A. K. Abbas, S. Hamad, and N. A. Hamad, 'Single line to ground fault detection and location in medium voltage distribution system network based on neural network', vol. 23, no. 2, pp. 621-632, 2021, doi: 10.11591/ijeecs.v23.i2.pp621-632.

[8] H. H. Goh et al., 'Transmission line fault detection: A review', Indones. J. Electr. Eng. Comput. Sci., vol. 8, no. 1, pp. 199-205, 2017, doi: 10.11591/ijeecs.v8.i1.pp199205.

[9] A. Bahmanyar, S. Jamali, A. Estebsari, and E. Bompard, 'A comparison framework for distribution system outage and fault location methods', Electr. Power Syst. Res., vol. 145, pp. 19-34, 2017.

[10] J. R. Abrams, 'Maximizing outage management systems through the use of interactive voice response', in Rural Electric Power Conference, 2003, 2003, pp. A1-A1.

[11] B. Amini, S. H. Khatoonabadi, and A. Zamanifar, 'Trouble call based outage determination in power distribution networks using ANFIS', in 2005 International Conference on Power Electronics and Drives Systems, 2005, vol. 2, pp. 1634-1639.

[12] H.-J. Chuang, C.-H. Lin, C.-S. Chen, C.-C. Yun, C.-Y. Ho, and C.-S. Li, 'Design of a knowledge based trouble call system with colored Petri net models', in 2005 IEEE/PES Transmission $\backslash \&$ Distribution Conference $\backslash \&$ Exposition: Asia and Pacific, 2005, pp. 1-6.

[13] X. Gu, H. Wang, and J. Chen, 'Application of rough setbased distribution network fault location approach in Trouble Call Management System', in 2012 China International Conference on Electricity Distribution, 2012, pp. 1-5.

[14] L. Yan, L. Jun, L. Wencai, and Z. Dening, 'Rural distribution network fault location algorithm based on fault complaint information', in 2011 Third International Conference on Measuring Technology and Mechatronics Automation, 2011, vol. 3, pp. 199-202.

[15] J.-T. Peng, C. F. Chien, and T. L. B. Tseng, 'Rough set theory for data mining for fault diagnosis on distribution feeder', IEE Proceedings-Generation, Transm. Distrib., vol. 151, no. 6, pp. 689-697, 2004.

[16] C.-F. Chien, S.-L. Chen, and Y.-S. Lin, 'Using Bayesian network for fault location on distribution feeder', IEEE Trans. Power Deliv., vol. 17, no. 3, pp. 785-793, 2002.

[17] A. Kusiak, 'Rough set theory: a data mining tool for semiconductor manufacturing', IEEE Trans. Electron. Packag. Manuf., vol. 24, no. 1, pp. 44-50, 2001.

[18] A. Farughian, L. Kumpulainen, and K. Kauhaniemi, 'Review of methodologies for earth fault indication and location in compensated and unearthed MV distribution networks', Electr. Power Syst. Res., vol. 154, pp. 373380, 2018, doi: 10.1016/j.epsr.2017.09.006.

[19] I. Dzafic and P. Mohapatra, 'Impedance based fault location for weakly meshed distribution networks', in ISGT 2011, 2011, pp. 1-6.

[20] S. H. Horowitz and A. G. Phadke, 'Nonpilot distance protection of transmission lines', in Power System Relaying, Wiley, 2008, pp. 101-132.

[21] Y. D. Liu, G. H. Sheng, Z. M. He, X. Y. Xu, and X. C. Jiang, 'Method of fault location based on the distributed traveling-wave detection device on overhead transmission line', in 2011 IEEE Power Engineering and Automation Conference, 2011, vol. 2, pp. 136-140.

[22] N. Gana, N. F. Ab Aziz, Z. Ali, H. Hashim, and B. Yunus, 'A comprehensive review of fault location methods for distribution power system', Indones. J. Electr. Eng. Comput. Sci., vol. 6, no. 1, pp. 185-192, 2017, doi: 10.11591/ijeecs.v6.i1.pp185-192.

[23] A. O. Ibe and B. J. Cory, 'A travelling wave-based fault locator for two-and three-terminal networks', IEEE Trans. power Deliv., vol. 1, no. 2, pp. 283-288, 1986.

[24] P. Jafarian and M. Sanaye-Pasand, 'A traveling-wavebased protection technique using wavelet/PCA analysis', IEEE Trans. Power Deliv., vol. 25, no. 2, pp. 588-599, 2010.

[25] A. M. Abeid, H. A. Abd El-Ghany, and A. M. Azmy, 'An advanced traveling-wave fault-location algorithm for simultaneous faults', in 2017 Nineteenth International Middle East Power Systems Conference (MEPCON), 2017, pp. 747-752.

[26] X. C. Jiang, D. Z. Wang, X. Q. Liu, and Y. Ning, 'Fault location on branched networks using a new travelingwave algorithm', in 2016 8th International Conference on Intelligent Human-Machine Systems and Cybernetics (IHMSC), 2016, vol. 2, pp. 221-224.

[27] X. Dong, S. Wang, and S. Shi, 'Research on characteristics of voltage fault traveling waves of transmission line', in 2010 Modern Electric Power Systems, 2010, pp. 1-5.

[28] M. Baù, R. Benato, S. Dambone Sessa, M. Poli, and C. Quaciari, 'Phase-to-ground fault location methods in unearthed sub-transmission networks: A review', AEIT 2016 - Int. Annu. Conf. Sustain. Dev. Mediterr. Area, Energy ICT Networks Futur., 2016, doi: 10.23919/AEIT.2016.7892761.

[29] M. Mirzaei, M. Z. A. Ab Kadir, E. Moazami, and H. Hizam, 'Review of fault location methods for distribution power system', Aust. J. Basic Appl. Sci., vol. 3, no. 3, pp. 2670-2676, 2009. 
[30] H. Livani and C. Y. Evrenosoluglu, 'A fault classification and localization method for three-terminal circuits using machine learning', IEEE Trans. Power Deliv., vol. 28, no. 4, pp. 2282-2290, 2013.

[31] S. Ebron, D. L. Lubkeman, and M. White, 'A neural network approach to the detection of incipient faults on power distribution feeders', IEEE Trans. Power Deliv., vol. 5, no. 2, pp. 905-914, 1990.

[32] C. Rangari and A. Yadav, 'A hybrid wavelet singular entropy and fuzzy system based fault detection and classification on distribution line with distributed generation', in 2017 2nd IEEE International Conference on Recent Trends in Electronics, Information $1 \&$ Communication Technology (RTEICT), 2017, pp. 14731477.

[33] A. Bahmanyar et al., 'Emerging smart meters in electrical distribution systems: Opportunities and challenges', in 2016 24th Iranian Conference on Electrical Engineering (ICEE), 2016, pp. 1082-1087.

[34] L. Kumpulainen, S. Pettissalo, and S. Sauna-Aho, 'A secondary substation monitoring based method for earthfault indication in MV cable networks', in Kaunas University of Technology and Aalto University organized seminar on Methods and techniques for earth fault detection, indication and location, Espoo, Finland, 2011.

[35] A. Von Meier, D. Culler, A. McEachern, and R. Arghandeh, Micro-synchrophasors for distribution systems. IEEE, 2014.

[36] G. Sanchez-Ayala, J. R. Agüerc, D. Elizondo, and M. Lelic, 'Current trends on applications of PMUs in distribution systems', in 2013 IEEE PES Innovative Smart Grid Technologies Conference (ISGT), 2013, pp. $1-6$.

[37] S. Jamali, A. Bahmanyar, and E. Bompard, 'Fault location method for distribution networks using smart meters', Meas. J. Int. Meas. Confed., vol. 102, no. February, pp. 150-157, 2017, doi: 10.1016/j.measurement.2017.02.008.

[38] R. A. F. Pereira, L. G. W. da Silva, M. Kezunovic, and J. R. S. Mantovani, 'Improved fault location on distribution feeders based on matching during-fault voltage sags', IEEE Trans. Power Deliv., vol. 24, no. 2, pp. 852-862, 2009.

[39] F. C. L. Trindade, W. Freitas, and J. C. M. Vieira, 'Fault location in distribution systems based on smart feeder meters', IEEE Trans. Power Deliv., vol. 29, no. 1, pp. 251-260, 2013.

[40] A. Estebsari, E. Pons, E. Bompard, A. Bahmanyar, and S. Jamali, 'An improved fault location method for distribution networks exploiting emerging LV smart meters', in 2016 IEEE Workshop on Environmental, Energy, and Structural Monitoring Systems (EESMS), 2016, pp. 1-6.

[41] S. F. Alwash, V. K. Ramachandaramurthy, and N. Mithulananthan, 'Fault-location scheme for power distribution system with distributed generation', IEEE Trans. Power Deliv., vol. 30, no. 3, pp. 1187-1195, 2014.

[42] F. C. L. Trindade and W. Freitas, 'Low voltage zones to support fault location in distribution systems with smart meters', IEEE Trans. Smart Grid, vol. 8, no. 6, pp. 2765-
2774, 2016.

[43] R. Calone, A. Cerretti, and A. Fatica, 'Evolution of the Fault Locator on MV distribution networks: from simple stand alone device, to a sophisticated strategic component of the Smart Grid control system', in Proc. 21st Int. Conf. Exhib. Electr. Distrib.(CIRED), 2011.

[44] E. Personal, A. Garcl'lia, A. Parejo, D. F. Larios, F. Biscarri, and C. León, 'A comparison of impedancebased fault location methods for power underground distribution systems', Energies, vol. 9, no. 12, p. 1022, 2016.

[45] A. Farughian, L. Kumpulainen, and K. Kauhaniemi, 'Review of methodologies for earth fault indication and location in compensated and unearthed MV distribution networks', Electr. Power Syst. Res., vol. 154, pp. 373380, 2018.

[46] A. Sheta, G. Abdulsalam, and A. Eladl, 'A Survey of Fault Location Techniques for Distribution Networks', Bull. Fac. Eng. Mansoura Univ., vol. 45, no. 2, pp. 1222, 2020, doi: 10.21608/bfemu.2020.98825.

[47] G. Druml, C. Raunig, P. Schegner, and L. Fickert, 'Fast selective earth fault localization using the new fast pulse detection method', 2013.

[48] B. Singh, N. K. Sharma, A. N. Tiwari, K. S. Verma, and S. N. Singh, 'Applications of phasor measurement units (PMUs) in electric power system networks incorporated with FACTS controllers', Int. J. Eng. Sci. Technol., vol. 3, no. 3, 2011 .

[49] E. Dusabimana and S.-G. Yoon, 'A survey on the micro-phasor measurement unit in distribution networks', Electronics, vol. 9, no. 2, p. 305, 2020.

[50] M. Majidi, A. Arabali, and M. Etezadi-Amoli, 'Fault location in distribution networks by compressive sensing', IEEE Trans. Power Deliv., vol. 30, no. 4, pp. 1761-1769, 2014.

[51] J. Ren, S. S. Venkata, and E. Sortomme, 'An accurate synchrophasor based fault location method for emerging distribution systems', IEEE Trans. Power Deliv., vol. 29, no. 1, pp. 297-298, 2013.

[52] U. Chakrabarti, A. Chakrabarti, and S. Sarkar, 'Fault detection in synchrophasor system by using Phasor Measuring Unit', 2015.

[53] A. Rajeev, T. S. Angel, and F. Z. Khan, 'Fault location in distribution feeders with optimally placed PMU's', in 2015 International Conference on Technological Advancements in Power and Energy (TAP Energy), 2015, pp. 438-442.

[54] M. U. Usman and M. O. Faruque, 'Validation of a PMU-based fault location identification method for smart distribution network with photovoltaics using real-time data', IET Gener. Transm. \\& Distrib., vol. 12, no. 21, pp. 5824-5833, 2018.

[55] J. Cordova and M. O. Faruque, 'Fault location identification in smart distribution networks with distributed generation', in 2015 North American Power Symposium (NAPS), 2015, pp. 1-7.

[56] M. Pignati, L. Zanni, P. Romano, R. Cherkaoui, and M. Paolone, 'Fault detection and faulted line identification in active distribution networks using synchrophasorsbased real-time state estimation', IEEE Trans. Power 
Deliv., vol. 32, no. 1, pp. 381-392, 2016.

[57] P. A. H. Cavalcante and M. C. de Almeida, 'Fault location approach for distribution systems based on modern monitoring infrastructure', IET Gener. Transm. I\& Distrib., vol. 12, no. 1, pp. 94-103, 2018.

[58] X. Chen and Z. Jiao, 'Accurate Fault Location Method of Distribution Network with Limited Number of PMUs', in 2018 China International Conference on Electricity Distribution (CICED), 2018, pp. 1503-1507.

[59] G. Filatova, A. Petrov, and M. Batmanov, 'Research of the Algorithm and the Prototype Device for Fault Location Based on Synchronized Two-Side Measurement', in 2020 International Youth Conference on Radio Electronics, Electrical and Power Engineering (REEPE), 2020, pp. 1-5.

[60] J.-S. Hong, G.-D. Sim, J.-H. Choi, S.-J. Ahn, and S.-Y. Yun, 'Fault location method using phasor measurement units and short circuit analysis for power distribution networks', Energies, vol. 13, no. 5, p. 1294, 2020.

[61] J. Nishanth, N. Palanichamy, and S. C. Lim, 'A Survey on the Characteristics and Requirements of Electricity Distribution Safety Technology', in 2020 4th International Conference on Intelligent Computing and Control Systems (ICICCS), 2020, pp. 709-713.

[62] M. Farajollahi, A. Shahsavari, E. M. Stewart, and H. Mohsenian-Rad, 'Locating the source of events in power distribution systems using micro-PMU data', IEEE Trans. Power Syst., vol. 33, no. 6, pp. 6343-6354, 2018. 